\title{
Anxiety-Inducing Dietary Supplements: A Review of Herbs and Other Supplements with Anxiogenic Properties
}

\author{
Caitlin E. McCarthy, Danielle M. Candelario, Mei T. Liu \\ Department of Pharmacy Practice and Administration, Ernest Mario School of Pharmacy, Rutgers, The State \\ University of New Jersey, Piscataway, USA \\ Email: c.mccarthy@rutgers.edu
}

Received 10 August 2014; revised 11 September 2014; accepted 20 September 2014

Copyright (C) 2014 by authors and Scientific Research Publishing Inc.

This work is licensed under the Creative Commons Attribution International License (CC BY). http://creativecommons.org/licenses/by/4.0/

(c) (i) Open Access

\section{Abstract}

Anxiety disorders comprise the most common group of mental disorders to affect the general population in the United States. These disorders are heterogeneous in nature, highly comorbid with one another, and pose a degree of difficulty regarding diagnosis and management. The exact etiology and pathophysiology of anxiety remains to be elucidated; however, it is likely that it is multifactorial, and all potential causes of anxiety must be investigated, including substance-induced anxiety. Among substances that may induce anxiety are dietary supplements. As utilization of these products appears to be high in the US population, it is important to identify which of available supplements may cause anxiety. Objective: To review the scientific literature to identify dietary supplements associated with induction of anxiety and related symptoms. Methods: A search of Natural Medicines Comprehensive Database, MedlinePlus Herbs and Supplements, and Natural Standard was performed to identify dietary supplements with anxiogenic properties. Dietary supplements were included based on product availability, utilization trends, and if there was sufficient evidence that the substance could elicit anxiety via direct pharmacologic effects. Agents were excluded from the review if anxiety was solely due to withdrawal from the substance or only occurred in the setting of intoxication. A search of MEDLINE and PUBMED was performed to identify relevant peer reviewed publications concerning induction of anxiety and/or its associated symptoms by those dietary supplements chosen for review. Conclusions: Dietary supplements can contribute to and cause anxiety and its related symptoms via overstimulation of the Central Nervous System. Healthcare professionals should screen all patients presenting with symptoms consistent with anxiety for recent or current use of all products capable of inducing anxiety, including dietary supplements. 


\section{Keywords}

\section{Anxiety, Adverse Effects, Dietary Supplements, St. John's Wort, Caffeine}

\section{Introduction}

"Natural products" is broadly used to describe a variety of agents, such as vitamins and minerals, probiotics, and herbs [1]. According to the National Center for Complementary and Alternative Medicine [2], "an herb (also called a botanical) can be any form of a plant or plant product, including leaves, stems, flowers, roots, or seeds which may be used for its scent, flavor, and/or therapeutic properties.” In the United States, the Dietary Supplement Health and Education Act of 1994 classifies herbs as dietary supplements. Dietary supplements are intended to supplement the diet and may not claim to diagnose, cure, mitigate, treat, or prevent illness; however, manufacturers are allowed to make claims regarding effects on the structure or function of the human body or role in promoting general well-being. Dietary supplements are regulated as foods and as such are not subject to the same rigorous regulatory requirements as pharmaceutical drugs. Therefore, they may be produced, sold, and marketed without first demonstrating safety or efficacy to the United States Food and Drug Administration (FDA) [3] [4].

According to a 2007 national survey, 55.1 million Americans have used an herb or supplement, with 17.9\% of total responders reporting use within the past 12 months. Of these responders, $45.4 \%$ disclosed use to a medical professional with the majority of these responders reporting use to a medical doctor. However, less than $1 \%$ of responders reported use to a pharmacist [5]. The relatively low disclosure rate is alarming as herbal supplements may interact with prescribed drugs and cause adverse reactions.

Anxiety disorders are a group of heterogeneous illnesses that share features of excessive fear and anxiety that persist beyond developmentally appropriate periods and result in related behavioral disturbances [6]. Anxiety disorders comprise the most prevalent group of mental disorders to affect the general US population with an estimated 12-month and lifetime prevalence rate of $19.0 \%$ and 31.0\%, respectively [7]. Examples of anxiety disorders include separation anxiety disorder, social anxiety disorder, panic disorder, generalized anxiety disorder, and substance/medication-induced anxiety disorder, among others [6]. The exact etiology and pathophysiology of primary anxiety disorders remain overwhelmingly unknown, and comorbidity among anxiety disorders and with other mental disorders is substantial, making appropriate diagnosis and management complicated [6].

Substance/medication-induced anxiety disorders (SMADs) are related to the physiological effects of a substance rather than an organically occurring disease as is seen with primary anxiety disorders. However, it is likely that the physiological effects of anxiety-inducing substances mimic that of primary anxiety disorders. Diagnosis of SMADs requires presence of prominent symptoms of anxiety or panic that are judged to be due to the effects of the substance and temporally associated with exposure to, intoxication with, or withdrawal from the substance. Patients with symptoms consistent with anxiety should be assessed for presence of SMADs as implicated substances range from drugs of abuse and toxins to medications and dietary supplements. Though prevalence is not clear and general population data suggests SMADs are rare, prevalence rates are likely to be higher in clinical populations [6]. According to the results of a one-year poison center surveillance project of dietary supplement adverse events, sympathetic nervous system stimulation was the most common type of adverse event to be reported, which included symptoms of anxiety [8].

Due to the lack of rigorous FDA regulatory requirements, potential safety concerns, high utilization, and low disclosure rates, it is important to screen patients with symptoms of anxiety for current or recent use of supplements with the potential to induce anxiety. The purpose of this article is to review dietary supplements that are associated with induction of anxiety symptoms via direct pharmacologic effects. The goal is to provide healthcare professionals with information regarding evidence of anxiety related to herbal supplement use in order to screen patients for the presence of substance-induced anxiety disorders and to make appropriate recommendations regarding the use of herbal supplements.

\section{Methods}

Natural Medicines Comprehensive Database, MedlinePlus Herbs and Supplements, and Natural Standard were 
initially screened for dietary supplements associated with induction of anxiety symptoms. A search of MEDLINE and PUBMED was conducted for relevant peer reviewed publications on the topics of selected herbal supplements and adverse effects associated with symptoms of anxiety. Agents were screened for inclusion based on current product availability in the United States, utilization trends in the United States, and evidence to support an ability to directly stimulate symptoms of anxiety or related symptoms due to the pharmacologic action of the agent. Agents were excluded if they induce anxiety solely as a consequence of poisoning or as a part of the sequelae of withdrawal, or if there was minimal evidence to support an ability to directly induce anxiety or related symptoms. Please do not revise any of the current designations.

\section{Serotonergic Agents, Jitteriness/Anxiety Syndrome, and Serotonin Syndrome}

While there are many theories regarding the etiology and pathophysiology of anxiety, the current target of firstline pharmacotherapy for the treatment of anxiety is founded in the serotonin component of anxiety. Though no definitive evidence exists to indicate that low serotonin levels is the cause of anxiety, it is postulated that serotonin dysregulation, and the consequential dysregulation of other neurotransmitters, likely contributes to the pathophysiology of the disease. Therefore, antidepressant agents, particularly the selective-serotonin reuptake inhibitors (SSRIs) and serotonin norepinephrine reuptake inhibitors (SNRIs), have become first-line options for the treatment of most anxiety disorders [9]. Likewise, herbal agents that are capable of modulating serotonin are often promoted for use in anxiety disorders. Unfortunately, serotonergic agents, pharmaceutical and herbal alike, are not without side effects, and through overstimulation, these agents are capable of causing jitteriness/anxiety syndrome and inducing serotonin syndrome.

Sinclair, et al. [10] describes jitteriness/anxiety syndrome as a phenomenon thought to be common in patients initiating therapy with antidepressants due to early activation. This phenomenon is marked by insomnia, anxiety, irritability, and increased energy, typically occurring during the first few weeks of therapy and secondary to an increase in serotonin function [9] [10].

Serotonin syndrome (SS) is a predictable consequence of excessive serotonin agonism at both central nervous system (CNS) and peripheral receptors. SS results in a triad of symptoms, including neuromuscular abnormalities, autonomic instability, and mental-status changes that occur within 24 hours of administration or overdose of at least one serotonergic agent. Symptoms can range in severity, from barely detectible to lethal. Two common findings in patients with excess serotonin agonism include anxiety and akathisia, and both may be observed in even mild forms of SS. However, anxiety and akathisia are often attributed to the psychiatric illness rather than to the drug therapy, and anxiety due to excess serotonin agonism may be overlooked [11]-[13].

A number of drugs and drug combinations have been associated with SS, including SSRIs, SNRIs, tricyclic antidepressants (TCAs), monoamine oxidase inhibitors (MAOIs), amphetamine and its derivatives, triptans, buspirone, and various drugs of abuse, over-the-counter (OTC) products, and herbal agents, among others [11] [14]. While the risk of developing SS may be higher in patients taking multiple serotonergic agents or who have considerable exposure to a single serotonergic agent, SS can occur even in patients taking a single agent at a therapeutic dose [15]. Therefore, it is important to screen patients with complaints of anxiety for any serotonergic medications, including herbal therapies, and to evaluate possible causality. The following agents with serotonergic properties are promoted for treatment of anxiety and may induce anxiety via the same mechanism.

\subsection{St. John's Wort (Hypericum perforatum)}

St. John's wort is one of the oldest and most robustly investigated medicinal herbs. St. John's wort is the common name for Hypericum perforatum, a yellow flowered perennial herb native to Europe, West Asia, and North America [16]. The important bioactive components of St. John's wort are concentrated in the buds, blossoms, and tips of the twigs of the plant [16]. It is available in a wide variety of formulations, including teas, tinctures, tablets, capsules, oils, and juice preparations from the raw drug, fluid and dried extracts, and pressed juices [16]. St. John's wort is commonly used for the treatment of mental health disorders, including mood and anxiety disorders, with the majority of positive efficacy evidence existing for its use in the treatment of depression [17].

The exact mechanisms of action remain unclear, though available research suggests that various bioactive constituents, including hypericin, pseudohypericin, hyperforin, and adhyperforin, among others, contribute to its pharmacologic effects [16] [18]. Evidence supports the hypothesis that St. John's wort is a non-specific inhibitor of synaptic reuptake of serotonin, norepinephrine, and dopamine, and it stimulates a downregulation of beta- 
adrenergic receptors and an upregulation of 5-HT2 receptors [16] [18]. Activity at benzodiazepine, adenosine, inositol, gamma-aminobutyric acid (GABA), N-methyl-D-aspartate (NMDA), and cholinergic receptors may also contribute to its clinical effects [18].

Symptoms of nervousness, including restlessness, anxiety, and agitation, are listed among common adverse effects in published studies of St. John's wort [18] [19]. In pooled data from the World Health Organization, the Medicines and Healthcare Products Regulatory Agency, and the Drug Commission of the German Medical Association, nervousness and anxiety associated with St. John's wort have been reported with relatively high frequency [19]. As of May 2001, there were 79 reports of nervous symptoms suspected to be adverse reactions to St. John's wort [19]. After paresthesia, headache and itching, and alongside skin erythema/rash and nausea, anxiety was listed among the third most frequently reported single adverse events related to St. John's wort [19].

In addition to reports of single adverse events of anxiety, case reports and case series of symptoms consistent with SS associated with St. John's wort have been published. SS has been reported in patients using St. John's wort in combination with prescription medications with serotonergic properties, including buspirone [20], various antidepressants, such as fluoxetine, paroxetine, sertraline, nefazodone [18] [21]-[23], and eletriptan [21]. In the aforementioned pooled data, there were 18 reports of possible interactions with SSRIs and St. John's wort resulting in SS [19]. SS has also been reported in patients using St. John's wort in combination with other herbal medications, including tryptophan [24], kava kava, and valerian root [25]. Even when used as monotherapy, cases of SS have been reported [26] [27].

It is also important to note that there is evidence that St. John's wort acts as a potent enzyme inducer, with a pronounced effect on cytochrome (CYP) P450 3A4 [28]. This may have a substantial impact on the effectiveness of pharmaceutical agents, as at least half of those agents currently available on the market are metabolized via this pathway, including a number of agents used for the treatment of anxiety [28]. While additional studies are needed to establish if and how St. John's wort may interact with specific agents, there is evidence that St. John's wort decreases the serum concentrations of alprazolam and amitriptyline, both of which may be used in the treatment of anxiety disorders [28] [29]. Due to the possibility of SS and reduction in serum concentration of agents that may be used for the treatment of anxiety, patient profiles must be carefully reviewed for potential drug interactions prior to recommending St. John's wort or prescribing new medications or adjusting doses in patients currently taking St. John's wort.

\subsection{S-Adenosylmethionine (SAMe)}

S-adenosylmethionine (SAMe) is a naturally occurring molecule that is widely distributed throughout the body [30]. SAMe serves as a methyl donator in enzymatic transmethylation for more than 100 biochemical reactions and contributes to the synthesis, activation, and/or metabolism of such compounds as hormones, neurotransmitters, nucleic acids, proteins, phospholipids, and certain drugs [30]. Common uses of SAMe include treatment of mental disorders, chronic pain disorders, and metabolic disorders, with the most positive evidence of efficacy demonstrated for use in depression and osteoarthritis [30].

The mechanism of action of SAMe for the treatment of anxiety and depression is unknown. However, SAMe serves as a methyl-donating cofactor in the rate-limiting step in the synthesis of serotonin, dopamine, and norepinephrine, and it is associated with elevated levels of these neurotransmitters [31]. In addition, neuroimaging studies reveal that the effects of SAMe on the brain are similar to those of conventional antidepressants, including TCAs, SSRIs, and SNRIs [32] [33]. SAMe is available in several salt forms with varying bioavailability and is often marketed as a single-agent product [30].

Although SAMe is generally well-tolerated, nervousness has been listed among general adverse effects [31]. In addition, its use in depressed patients has been associated with anxiety [30]. In a small pilot study, the safety and efficacy of SAMe administered in doses of 800 to $3600 \mathrm{mg}$ per day for a 10-day duration was evaluated for the treatment of depression in patients with Parkinson's disease who failed trials with other antidepressant agents [34]. Two of the 13 enrolled patients (15.4\%) prematurely withdrew from the trial due to reports of increased anxiety [34]. In a double blind, randomized trial evaluating augmentation with SAMe in serotonin reuptake inhibitor nonresponders with major depressive disorder, activation (defined as symptoms of restlessness, anxiety, jitters, or irritability), was reported in 3 of 39 (7.7\%) patients receiving antidepressant plus SAMe [35]. However, activation was also reported in 4 of the 34 (11.8\%) patients receiving antidepressant plus placebo, and the difference did not reach statistical significance [35]. 
In addition to reports of anxiety and nervousness in clinical trials, SAMe also has the theoretical ability to induce SS. Iruela, et al. [36] described a potential case of SS marked by anxiety, agitation, and confusion in a patient taking SAMe and clomipramine. To our knowledge, there have been no additional published reports of SS in patients taking SAMe. Due to evidence of nervousness and anxiety in clinical trials, and the potential to induce SS, use of SAMe in individuals with anxiety disorders or those prone to anxiety is possibly unsafe, and use with other serotonergic agents should be avoided.

\subsection{Tryptophan and 5-Hydroxytryptophan (5-HTP)}

Tryptophan is an essential amino acid that is converted into 5-Hydroxytryptophan (5-HTP) [37]. 5-HTP is structurally and functionally related to serotonin (5-HT) as 5-HTP is converted to 5-HT in the presence of vitamin B6 [37]. Increased tryptophan concentrations in the brain have been shown to raise serotonin release, and it is likely that 5-HTP and its conversion to serotonin are dependent on the availability of tryptophan [38]. Tryptophan and 5-HTP are commonly used for the treatment of conditions in which a lack of serotonin is thought to contribute to the etiology or pathophysiology of the disease. Both are often used for the treatment of various mental disorders and may be used in the treatment of chronic pain and neurologic disorders [39] [40].

Both tryptophan and 5-HTP have a theoretical ability to induce anxiety symptoms via stimulation of serotonin synthesis. As previously mentioned, SS has been reported in a patient taking St. John's wort in combination with tryptophan [24]. In rat models, administration of 5-HTP in doses of 100 to $200 \mathrm{mg} / \mathrm{kg}$ induces SS [38]. To our knowledge, there have been no reports of SS related to 5-HTP consumption in humans; however, the possibility cannot be ruled out. The risk is likely higher when used in combination with other serotonergic medications.

In addition to serotonergic medications, those drugs that can inhibit the metabolism of 5-HTP and improve its ability to cross the blood brain barrier would also theoretically increase this risk. Of note, carbidopa has been used in combination with 5-HTP for the treatment of myoclonus in order to block peripheral break down of 5-HTP and enhance its ability to cross the blood brain barrier [41]-[43]. Such a combination may result in higher CNS concentrations of 5-HTP, and consequently 5-HT, potentially increasing risk of SS.

In general, use of tryptophan is considered to be unsafe as it has been linked to over 1500 reports of eosinophilia myalgia syndrome (EMS) and several deaths [39]. Use of 5-HTP should also be avoided as it may cause asymptomatic eosinophilia or EMS and is possibly unsafe, though evidence of an association is not as strong as with tryptophan [40].

\section{Caffeinated Central Nervous System Stimulants}

Caffeine is found naturally in over 60 species of plants such as coffee (Coffea robusta/arabica), tea (Camellia sinensis), cocoa (Theobroma cacao), guarana (Paullinia cupana), yerba mate (Ilex paraguariensis) and kola nut (Cola nitida/acuminata) [44]. These plants and their extracts are regularly consumed as part of a normal diet. Additionally, caffeine can be found in other substances such as soft drinks, energy drinks, chocolate, dietary supplements, and medications. In the United States, it is estimated that average caffeine consumption is approximately $4 \mathrm{mg} / \mathrm{kg}$ per day in the adult population [45]. Caffeine can increase wakefulness, improve mental alertness, increase attention, reduce reaction time, and decrease fatigue. It has also been suggested that caffeine may help reduce risk factors for metabolic syndromes, such as type 2 diabetes mellitus and obesity, and reduce symptoms associated with Parkinson's disease [45].

Caffeine is a trimethylxanthine closely related to theophylline. The main mechanism of action of caffeine is nonselective inhibition of adenosine receptors and phosphodiesterase, which can result in CNS stimulation and increased levels of dopamine, norepinephrine and serotonin in the brain. Caffeine is rapidly and completely absorbed with peak plasma concentration reached at 30 minutes post-consumption. It is metabolize extensively in the liver with an elimination half-life of 5 hours [44] [46]. At the lower dose range of 70 to $100 \mathrm{mg}$, caffeine exhibits linear pharmacokinetics. However, the clearance of caffeine is reduced and the elimination half-life is prolonged at the higher dose range of 250 to $500 \mathrm{mg}$ [45].

Caffeine generally causes no adverse health effects when consumed in moderation (less than or equal to 400 $\mathrm{mg} /$ day or $6.5 \mathrm{mg} / \mathrm{kg} /$ day for a $70 \mathrm{~kg}$-adult) [45]. Toxicity from caffeine is rare as most adults can develop tolerance from chronic consumption. An estimated lethal dose of caffeine is 150 to $200 \mathrm{mg} / \mathrm{kg}$ or 10 to 20 gm/day; however, significant symptoms were reported in one adult who consumed $1 \mathrm{gm}$ of caffeine. Early symptoms of acute caffeine toxicity include anorexia, tremor, restlessness, nausea, vomiting, and tachycardia [46]. 
At higher doses or in susceptible individuals, caffeine can lead to "caffeinism” which can present as anxiety, nervousness, dysphoria, insomnia, excitement, psychomotor agitation, and rambling speech [47]. A study in light, nondependent caffeine users (average caffeine consumption of $116 \mathrm{mg} /$ week) has found that caffeine can cause anxiety symptoms at a dose of $450 \mathrm{mg}$, but the same effect is not seen at lowers doses of $50 \mathrm{mg}$ or $150 \mathrm{mg}$ [48]. In addition to dose, the anxiogenic effect is also dependent on individual factors such as caffeine preference, baseline psychiatric disorders, and genetic background [47]. Patients with a history of panic disorder, general anxiety disorder, performance social anxiety disorder, or major depressive disorders are more vulnerable to the anxiogenic effects of high dose caffeine (greater than $400 \mathrm{mg}$ ) [47] [49] [50]. Genetics may also play an important role, as individuals with 1976T/T genotypes for A2A adenosine receptors exhibit a greater increase in anxiety after caffeine consumption [47] [51].

Although caffeine can have beneficial health effects when consumed in moderation, higher doses can have a negative impact on psychiatric symptoms. While most caffeinated substances do not pose a health concern when used individually at moderate doses, risk of adverse effects increases when multiple caffeine-containing agents are used together or when high doses are consumed. As caffeine-containing products are common, patients should be aware of additive effect, especially when considering products such as energy drinks and weight loss supplements.

The following substances can be associated with anxiety and its related symptoms through CNS stimulation due to caffeine content.

\subsection{Tea (Camellia sinensis)}

Second to water, tea is the most commonly consumed beverage in the world. It is commonly used for short-term relief of mental and physical fatigue, increased performance capabilities, and promotion of mental alertness [44] [52]. The beneficial effects of tea could be due to the high levels of antioxidant such as polyphenol catechins which can have free-radical scavenging properties and inhibition of inflammation. In studies evaluating the effects of tea consumption, a number of health benefits were seen. Tea is associated with a reduced risk of stroke and depression and improved metabolic profiles, including positive effects on glucose levels, lipids, weight, and blood pressure [52].

The adverse effects associated with tea are related to the caffeine content. An 8 ounce cup of green or black tea contains approximately 14 to $61 \mathrm{mg}$ of caffeine [52]. Despite evidence of proven health benefits, patient should avoid heavy daily consumption of tea as high dose caffeine intake is associated with insomnia, anxiety, restlessness, and tachycardia.

\subsection{Coffee (Coffea robusta/arabica)}

Coffee is the third most commonly consumed beverages in the world and serves as the main source of caffeine intake in adults in the western countries [44] [52]. Coffee consumption is associated with a lower risk of heart failure, stroke, diabetes mellitus, and reduced rate of all-cause and cardiovascular mortality [52]. Consumption of coffee, not tea, has shown to have an inverse relationship with Alzheimer's disease [44].

Similar to tea, the adverse effects associated with coffee are related to the caffeine content. An 8 ounce cup of coffee contains 95 to $200 \mathrm{mg}$ of caffeine [52]. Patient should avoid heavy daily consumption of coffee as high dose caffeine intake can cause insomnia and anxiety. Additionally, increased risk for fracture has been observed in women and high caffeine intake may increase calcium and magnesium urinary excretion which can affect bone health [52].

\subsection{Cocoa (Theobroma cacao)}

Cocoa, also known as Cacao, is derived from the seeds of the Theobroma cacao L. tree and it is commonly used as an ingredient in food products, such as chocolate [53]. Cocoa is a complex plant product that contains over 300 different constituents. Its major components include cocoa butter, minerals, methylxanithines (theobromine $1 \%$ to $4 \%$ and caffeine $0.07 \%$ to $0.36 \%$ ), and polyphenols [54] [55]. It has been shown to have various health benefits, such as reduced body weight, enhanced cognition, protection against insulin resistance, and anti-inflammatory properties [56]. Consumption of cocoa and chocolate has also been shown to potentially prevent depression due to the conversion of cocoa-derived tryptophan into serotonin in one animal study [54]. Cocoa is 
generally well tolerated, but it can cause allergic skin reactions, shakiness, increased urination, increased heart rate, constipation, and migraine headaches in some patients. Although the concentration of caffeine in cocoa is low, it may have additive effects when used with other caffeine-containing products and increase the risk of adverse effects [55].

\subsection{Cola Nut (Cola nitida/acuminata)}

The cola nut, also called kola, is from the Cola species originating in western Africa. Commercially available cola nuts are cultivated primarily from seeds of two species: Cola nitida and Cola acuminata. The cola nut comprises the bulk of the seed, is brownish in color, and is approximately the size of a chestnut. When fresh, it is bitter tasting, but after drying, the taste becomes mild with an odor similar to nutmeg. Caffeine content of herbal preparation of cola nut extracts varies between 1.5\% to 3.8\% [57]. Cola nut can be used for short-term relief of mental and physical fatigue, weight loss, depression, and migraines. Cola nut extract is also used in the food industry as a natural flavoring agent [57] [58].

Cola nut acts as a potent CNS stimulant due to its high concentration of caffeine, and adverse effects are usually related to the caffeine content. In one animal study, cola nut extract exhibited a more gradual onset but similar neurostimulatory effects as compared to caffeine. Cola nut has been listed as an herb that can cause irritation to the gastrointestinal tract and should not be used during pregnancy unless the potential benefits outweigh the potential risk [57].

\subsection{Guarana (Paullinia cupana)}

Guarana, also called guaranine, is a rainforest vine native to the Amazon and it belongs to the subfamily Sapindoideae. The seeds from the guarana fruit are usually dried or roasted and contain $2.5 \%$ to $6 \%$ of caffeine compared to $1 \%$ to $2 \%$ in coffee. Other alkaloids, such as theobromine and theophylline, were also found in small quantity in guarana [59] [60]. Due to its stimulating properties from the caffeine content, guarana has long been used by the Amazon Indians from Maues for the purpose of hunting over long periods of time. It has also been used as a tonic to promote functioning of the kidneys, muscles, heart, stomach, and intestines, to treat high cholesterol, to reduce appetite, and to improve sexual potency [60]. Adverse effects from guarana are usually related to the caffeine content. In a single-blind, placebo-controlled study by Silvestrini et al. [61], healthy subjects were given 3 capsules of $360 \mathrm{mg}$ of guarana extract daily for 5 days to assess the psychological effects of commercial products containing guarana. The study did not find that guarana has an effect on psychological wellbeing, anxiety, or mood [61]. However, the lack of benefit or adverse effects seen in this study may be attributable to the relatively low total daily dose administered, as $1080 \mathrm{mg} /$ day of guarana is approximately equal to 27 $\mathrm{mg} /$ day of caffeine [61].

Guarana can be found among ingredients listed in energy drinks, and there have been reports of psychiatric adverse effects such as anxiety, restlessness, and irritability associated with energy drinks. Although the amount of guarana found in energy drinks is usually too low to elicit therapeutic benefits or adverse effects, the psychiatric disturbance can be a result of heavy consumption. In addition to the caffeine already present in energy drinks, guarana can increase the total caffeine content by $60 \mathrm{mg}$ per drink. Adolescents seem to be more vulnerable to these adverse effects and heavy use of energy drinks in this population should be discouraged [62] [63].

\subsection{Yerba Mate (Ilex paraguariensis)}

Mate, also known as yerba mate, is an herbal beverage made from the dried leaves of Ilex paraguariensis, a plant of the Aquifoliaceae family. It is commonly used in southern Latin American countries, such as southern Brazil, Argentina, Paraguay, and Uruguay, as a source of caffeine and for its medicinal properties. It is commercially available in the United States as individual packed tea bags, oral capsules, or as mate tea concentration for use as an ingredient in the food and dietary supplement industries [64] [65]. It contains numerous active phytochemicals that may be responsible for its health benefits. The two compounds found in the highest concentration are the polyphenols (chlorogenic acid) and xanthines (caffeine and theobromine) followed by purine alkaloids, flavonoids, amino acids, minerals and vitamins such as vitamin C, B1 and B2 [64]. Of the various xanthines that are found in mate, caffeine has the highest concentration ( $1 \%$ to $2 \%$ of dry weight), which may be responsible for its pharmacologic effects. The concentration of caffeine in mate tea is approximately 78 mg per cup (150 
$\mathrm{mL}$ ), which is similar to the caffeine content in coffee [64]. In addition to reducing fatigue via CNS stimulation, mate has also been used as an antioxidant, diuretic, mild analgesic, weight loss supplement, lipid-lowering agent, and for the treatment of urinary tract infections. Adverse effects from mate are usually related to the caffeine content. Chronic and heavy consumption has been associated with development of oral, esophageal, lung, bladder and kidney cancer in epidemiological studies [64] [66]. The data regarding its carcinogenic risk is inconclusive at this point, but contamination with alkylating agents during the drying process of the leaves may be responsible. Until more is known about its carcinogenic potential, patients should be discouraged from using mate [65].

\section{Non-Caffeinated Central Nervous System Stimulants}

The following herbal supplements can be associated with anxiety and its related symptoms via CNS stimulation through a variety of proposed mechanisms.

\subsection{Khat (Catha edulis)}

Khat, or Catha edulis from the Celastraceae family, is native to East Africa and some countries of the Arabian peninsula where it is cultivated and harvested throughout the year [67] [68]. Its use is generally limited to these regions as it is believed that leaves of this flowering evergreen must be fresh in order to elicit the desired stimulating effects, which are thought to decline within 48 hours after the leaves are removed from the tree and dried [67] [69] [70]. Traditionally, the leaves of this shrub are used in social settings for their euphoric effects, most notably by men during cultural based activities [67] [68] [71]. Chewers will use the leaves and shoots, swallowing the juice and rejecting the residues. Doses may vary, but it has been reported that approximately 100 to 200 grams of young fresh leaves are favored due to increased potency and tenderness [67] [71]. It is estimated that five to ten million people chew Khat on a daily basis [70] [72]. To help facilitate global use, air transport and immigrant importation has increased distribution to areas where Khat is not a native plant [73] [74]. US Customs report that smugglers bring in fresh Khat on Thursdays, Fridays, and Saturdays for weekend use, through methods of freezing as preservation to maintain its potency [67].

The active constituents of Khat are cathinone and cathine (norpseudoephedrine). Both closely resemble amphetamine in chemical structure, with the key difference being the carbonyl group of cathinone, where one may find a methylene group on the amphetamine side-chain. An analysis of Khat samples show variation in cathinone content depending on country of origin, ranging from $0.9 \%$ to $3.3 \%$ [75]. As these compounds are all derivatives of phenethylamines, Khat has been considered a "natural amphetamine" with symptoms reminiscent of those induced by its more well-known analogue [74]. Like amphetamine, Khat has sympathomimetic effects lending to increases in blood pressure, heart rate, temperature, and mydriasis [76] [77]. Psychostimulatory effects such as delusions, paranoia, irritability, nervousness, hyperactivity, anxiety, and toxic psychosis have all been reported in association with Khat or its constituents [67] [68] [74] [76]-[79]. In a Yemen study of healthy adult volunteers, Hassan et al. [80] specifically addresses anxiety and depression as a temporary effect of Khat after 3 hours of chewing. However, this effect was found to disappear the next day [80] Although large, randomized clinical data is limited regarding the direct anxiogenic effects of Khat, the stimulatory effects of its components is often directly compared to amphetamines which has been previously correlated to anxiety.

There are no well-designed clinical trials validating the use of Khat in traditional medicine and its use is primarily recreational. The stimulating effect increases alertness and energy and induces a feeling of elation, wellbeing, and enhanced imagination [69] [70]. Its ability to ward off fatigue, improve attention, and reduce appetite is appealing to students, laborers [71] [74], and drivers, where it has been described as a contributor to road traffic injuries in Ethiopia [79] [81]. The negative socio-economic impact [82] and the documented addictive properties of Khat led the World Health Organization (WHO) to declare it as a highly addictive drug in 1980. Cathinone and cathine are also listed in the 1971 United Nations Convention on Psychotropic Substances under Schedules I and III, respectively. In the Unites States, under the Drug Enforcement Agency (DEA) and Controlled Substance Act, cathine is a Schedule IV stimulant, and cathinone and Khat are illegal Schedule I stimulants due to lack of accepted safety issues [83]. Patients should be advised against the recreational use of Khat due to addictive potential and cardiovascular and CNS effects.

\subsection{Yohimbine (Pausinystalia yohimbe)}

Yohimbine, or Pausinystalia yohimbe from the Rubiaceae family, is an alkaloid extract found in the bark of the 
West African yohimbe tree [84] [85] and has been used for over 100 years as an aphrodisiac for the treatment of impotence [85]. Yohimbine's pharmacologic activity has not been completely elucidated in humans. However, its clinical effects are attributed to potent alpha2-adrenergic receptor antagonism, which may increase penile blood flow and CNS activity resulting in increased parasympathomimetic and cholinergic activity [85] [86]. The erectogenic effect is likely multifactorial as it may treat various forms of impotence [85] and sexual dysfunction caused by SSRIs [86] [87].

For problems with sexual performance, the typical dose of yohimbine is based on the most commonly used dosages in the current literature with oral doses ranging from 15 to $100 \mathrm{mg}$ daily in divided doses, although this practice is not standardized with most trials administering yohimbine once daily [84] [88] [89]. Yohimbine is currently available in several sexual enhancement products [90], and in combination with other drugs or supplements, such as caffeine, there has been noted additional positive effects on sexual function [91]. However, the amount of active yohimbine alkaloid varies markedly between non-standardized herbal products with Betz et al. [92] noting little to no plant material in commercial products.

In addition to the peripheral alpha2-adrenoceptor antagonism, it has been postulated that yohimbine plays a role in central modulation, stimulating noradrenergic (NA) cell firing and release [86]. This central NA activity has been previously proposed as a contributor to negative emotions such as anxiety and/or fear [93]. Yohimbine's central activity thus may contribute to the anxiogenic symptoms associated with its administration. During a six-year retrospective review of California Poison Control reporting, there were approximately 238 reported cases of yohimbine adverse events. The frequency of anxiety/agitation related adverse events was reported to be $32.9 \%$ [94].

Anxiety has been reported to occur in doses ranging from 30 to $60 \mathrm{mg}$ [95]-[97], and in healthy adults with no medical history, increased symptoms of panic have been noted [98]. More importantly, patients with preexisting psychiatric disorders, such as anxiety disorder, panic disorder, and posttraumatic stress disorder, may be at increased risk for triggering acute symptoms of anxiety and panic after yohimbine exposure [99]-[102]. In panic disorder patients, $63 \%$ reported symptoms similar to those of their naturally occurring panic attacks after intravenous administration of yohimbine $(0.4 \mathrm{mg} / \mathrm{kg})$ [100]. Albus et al. [102] noted more pronounced anxiety and panicky ratings in panic patients compared with controls after administering $20 \mathrm{mg}$ of yohimbine. The findings of these investigations suggest anxiety and panic disorders may occur in a variety of users, and all patients, particularly those with psychiatric disorders, should be advised of the anxiogenic effects associated with yohimbine use.

\subsection{Ephedra (Ephedra sinica)}

As an evergreen shrub-like plant native to Central Asia and Mongolia, Ephedra sinica is the most common source of ephedra (Mua Huang) [103]. The principal active ingredient found in the stem and leaf of the tree is ephedrine, which has been used in traditional Chinese medicine for thousands of years to treat colds, fever, headaches, asthma, wheezing, and nasal congestion [104] [105]. This should be distinguished from Mormon tea which lacks ephedrine and its associated side effects. In the United States, ephedra products were marketed for weight loss, weight management, energy enhancement, and athletic performance until its ban in 2004 with over 200 over-the-counter products available in the late 1990's [103]. In a multistate survey of US adults conducted between 1996 and 1998, 7\% or respondents reported overall nonprescription weight loss product use, and 1\% reported ephedra product use [106].

The primary mechanism of action of ephedrine's weight loss effect is CNS stimulation, resulting from increased release of norepinephrine and dopamine. Mild cardiovascular and CNS stimulant effects include headache, tremor, sweating, palpitations, and insomnia. More severe effects that may occur after overdose include anxiety, agitation, psychosis, seizures, palpitations, and chest pain [107]. Thus, ephedrine's use is contraindicated in patients with history of heart disease and patients with chronic anxiety/psychiatric disorders, among others. Side effects of anxiety, tremulousness, insomnia, and personality changes were known to exacerbate underlying conditions [108]. In 2004, the FDA banned the sale of ephedra-containing dietary supplements in the United States. The FDA identified these supplements to have an unreasonable risk of injury or illness [109]. This ruling was based on peer reviewed scientific literature and a number of reports of increased sympathetic activity leading to increased blood pressure and heart rate and reports of serious cardiac toxicity and cerebrovascular events in persons taking ephedrine [109] [110]. Ephedra-containing botanicals products are much more 
likely to result in severe medical outcomes than those without ephedra [111], and Bent et al. [112] described the increased relative risk for adverse reactions of Ephedra as compared to other commonly used herbal products. In combination products, ephedra has often been combined with caffeine and guarana, which has been associated with increased adverse effects and toxicity [113] [114].

Although ephedra is on the list of currently banned items in the United States, its use remains prevalent among athletes attempting to enhance athletic performance [115], and health authorities have struggled to control its public use despite government regulation [116]. Additionally, the 2004 FDA ban did not apply to traditional ephedra herbal teas regulated as conventional foods that may still be available in traditional Chinese stores and through illicit channels. Thus, the use of ephedrine may be underestimated. Due to potentially dangerous outcomes, patients should be cautioned against its use.

\subsection{Country Mallow (Sida cordifolia)}

Country Mallow as it is known in English may also be referred to as malva branca (white mallow) in Brazil and bala in India as it is extensively used as an herbal drug in these countries [117] [118]. Country mallow may also be referred to by its scientific name Sida cordifolia Linn as a part of the Malvaceae family [117]. This bush can grow up to $2 \mathrm{~m}(6.5 \mathrm{ft})$ in height, with light green leaves oval-elongated in shape and white or yellow flowers [118] [119].

The plant Sida cordifolia mainly contains alkaloids, fatty oils, and steroids [120] [121]. The various portions of the plant such as the root, stem, and leaves have all demonstrated varying degrees of anti-inflammatory [119] [120], analgesic [119]-[122], antimicrobial [121], and hypoglycemic activity [120] in animal models. Research is generally limited to animal or in vitro studies, and clinical evaluation in humans is lacking, leaving insufficient evidence regarding the effectiveness of county mallow [117]. Country mallow is available as a $300 \mathrm{mg}$ strength supplement and may be used as a tea infusion or in oral formulations [118]. As a tea infusion, it is commonly used for colds, flu, asthma, bronchitis, inflammation, and fluid retention. In herbal combination products, country mallow is used for weight loss, fat burning, and to increase energy [117] [118].

Chemical analysis of country mallow has mainly demonstrated the presence of sympathomimetic amines and ephedrine [121]. Animal studies appear to find aqueous extracts to have low toxicity [119] [122]; however, large doses may cause or exacerbate anxiety due to the associated CNS stimulant effects of ephedrine. There are no studies linking Country Mallow directly to anxiety; however, it is proposed that the effect would be comparable.

In the 2004 FDA ban on ephedra-containing dietary products, ephedrine alkaloids such as Sida cordifolia were also included [109] [123]. However, the product is still available from overseas vendors through internet purchasing. Due to insufficient evidence regarding efficacy and regulatory safety concerns, patients should be advised against the use of Country Mallow and Ephedra as the potential risks currently outweigh any potential benefits [117].

\section{Discussion and Conclusions}

There are a number of dietary and herbal supplements available commercially and used globally that appear to have the potential to cause anxiety and associated symptoms, including serotonergic agents, caffeinated products, and CNS stimulants. As dietary supplements are not subject to the same regulatory requirements as conventional medications, published research is limited, and the exact mechanisms of action of available dietary supplements remain overwhelmingly unknown. However, from what is known about the pharmacologic activities of these supplements and their constituents, it appears that overstimulation of the CNS is a common theme. For the most part, when used in moderation and at established therapeutic doses, the risk of causing anxiety with these supplements is relatively low. However, risk appears to increase when consumption is higher than recommended therapeutic ranges or when used in combination with other agents that exhibit similar pharmacologic effects.

Due to the relatively high utilization of dietary supplements and relatively low disclosure rates to conventional medical professionals, notably, pharmacists, it is imperative that comprehensive medication profiles include dietary supplements. Those presenting with symptoms consistent with anxiety should be screened for recent or current use of all products capable of inducing anxiety, including dietary supplements. It is also important to consider the risk of inducing or exacerbating anxiety symptoms, especially in those with a history of psychiatric disorders, when recommending use of dietary supplements. 


\section{References}

[1] National Center for Complementary and Alternative Medicine (US) (2013) Complementary, Alternative, or Integrative Health: What's in a Name? http://nccam.nih.gov/health/whatiscam

[2] National Center for Complementary and Alternative Medicine (US) (2006) Herbal Supplements: Consider Safety, Too. http://img.thebody.com/nccam/safety.pdf

[3] Bent, S. (2008) Herbal Medicine in the United States: Review of Efficacy, Safety, and Regulation: Grand Rounds at University of California, San Francisco Medical Center. Journal of General Internal Medicine, 23, 854-859. http://dx.doi.org/10.1007/s11606-008-0632-y

[4] Cupp, M.J. (1999) Herbal Remedies: Adverse Effects and Drug Interactions. American Family Physician, 59, 12391245.

[5] Wu, C.H., Wang, C.C. and Kennedy, J. (2011) Changes in Herb and Dietary Supplement Use in the US Adult Population: A Comparison of the 2002 and 2007 National Health Interview Surveys. Clinical Therapeutics, 33, 1749-1758. http://dx.doi.org/10.1016/j.clinthera.2011.09.024

[6] American Psychiatric Association (2013) Diagnostic and Statistical Manual of Mental Disorders. 5th Edition, American Psychiatric Association, Arlington.

[7] Kessler, R.C., Aguilar-Gaxiola, S., Alonso, J., et al. (2009) The Global Burden of Mental Disorders: An Update from the WHO World Mental Health (WMH) Surveys. Epidemiologia e Psichiatria Sociale, 18, 23-33. http://dx.doi.org/10.1017/S1121189X00001421

[8] Haller, C., Kearney, T., Bent, S., Ko, R., Benowitz, N. and Olson, K. (2008) Dietary Supplement Adverse Events: Report of a One-Year Poison Center Surveillance Project. Journal of Medical Toxicology, 4, 84-92. http://dx.doi.org/10.1007/BF03160960

[9] Bandelow, B., Sher, L., Bunevicius, R., et al. (2012) Guidelines for the Pharmacological Treatment of Anxiety Disorders, Obsessive-Compulsive Disorder and Posttraumatic Stress Disorder in Primary Care. International Journal of Psychiatry in Clinical Practice, 16, 77-84. http://dx.doi.org/10.3109/13651501.2012.667114

[10] Sinclair, L.I., Christmas, D.M., Hood, S.D., et al. (2009) Antidepressant-Induced Jitteriness/Anxiety Syndrome: Systematic Review. The British Journal of Psychiatry, 194, 483-490. http://dx.doi.org/10.1192/bjp.bp.107.048371

[11] Boyer, E.W. and Shannon, M. (2005) The Serotonin Syndrome. The New England Journal of Medicine, 352, 11121120. http://dx.doi.org/10.1056/NEJMra041867

[12] Birmes, P., Coppin, D., Schmitt, L. and Lauque, D. (2003) Serotonin Syndrome: A Brief Review. Canadian Medical Association Journal, 168, 1439-1442.

[13] Evans, C.E. and Sebastian, J. (2007) Serotonin Syndrome. Emergency Medicine Journal, 24, e20. http://dx.doi.org/10.1136/emj.2006.040550

[14] Mills, K.C. (1997) Serotonin Syndrome. A Clinical Update. Critical Care Clinics, 13, 763-783. http://dx.doi.org/10.1016/S0749-0704(05)70368-7

[15] Ables, A.Z. and Nagubilli, R. (2010) Prevention, Diagnosis, and Management of Serotonin Syndrome. American Family Physician, 8, 1139-1142.

[16] Linde, K. (2009) St. John’s Wort-An Overview. Forschende Komplementärmedizin, 16, 146-155. http://dx.doi.org/10.1159/000209290

[17] Henderson, L., Yue, Q.Y., Bergquist, C., Gerden, B. and Arlett, P. (2002) St John’s Wort (Hypericum perforatum): Drug Interactions and Clinical Outcomes. British Journal of Clinical Pharmacology, 54, 349-356. http://dx.doi.org/10.1046/j.1365-2125.2002.01683.x

[18] Hammerness, P., Basch, E., Ulbricht, C., Barrette, E.P., Foppa, I., Basch, S., et al. (2003) St John’s Wort: A Systematic Review of Adverse Effects and Drug Interactions for the Consultation Psychiatrist. Psychosomatics, 44, 271-282. http://dx.doi.org/10.1176/appi.psy.44.4.271

[19] Knüppel, L. and Linde, K. (2004) Adverse Effects of St. John’s Wort: A Systematic Review. Journal of Clinical Psychiatry, 65, 1470-1479. http://dx.doi.org/10.4088/JCP.v65n1105

[20] Dannawi, M. (2002) Possible Serotonin Syndrome after Combination of Buspirone and St. John's Wort. Journal of Psychopharmacology, 16, 401. http://dx.doi.org/10.1177/026988110201600420

[21] Bonetto, N., Santelli, L., Battistin, L. and Cagnin, A. (2007) Serotonin Syndrome and Rhabdomyolysis Induced by Concomitant Use of Triptans, Fluoxetine and Hypericum. Cephalalgia, 27, 1421-1423. http://dx.doi.org/10.1111/j.1468-2982.2007.01430.x

[22] Lantz, M.S., Buchalter, E. and Giambanco, V. (1999) St. John’s Wort and Antidepressant Drug Interactions in the Elderly. Journal of Geriatric Psychiatry and Neurology, 12, 7-10. http://dx.doi.org/10.1177/089198879901200103 
[23] Gordon, J.B. (1998) SSRIs and St. John’s Wort: Possible Toxicity? American Family Physician, 57, 950.

[24] Bryant, S.M. and Kolodchak, J. (2004) Serotonin Syndrome Resulting from an Herbal Detox Cocktail. The American Journal of Emergency Medicine, 22, 625-626.http://dx.doi.org/10.1016/j.ajem.2004.09.013

[25] Beckman, S.E., Sommi, R.W. and Switzer, J. (2000) Consumer Use of St. John's Wort: A Survey on Effectiveness, Safety, and Tolerability. Pharmacotherapy: The Journal of Human Pharmacology and Drug Therapy, 20, 568-574. http://dx.doi.org/10.1592/phco.20.6.568.35152

[26] Parker, V., Wong, A.H., Boon, H.S. and Seeman, M.V. (2001) Adverse Reactions to St. John's Wort. Canadian Journal of Psychiatry, 46, 77-79.

[27] Brown, T.M. (2000) Acute St. John’s Wort Toxicity. The American Journal of Emergency Medicine, 18, 231-232. http://dx.doi.org/10.1016/S0735-6757(00)90030-5

[28] Markowitz, J.S., Donovan, J.L., DeVane, C.L., Taylor, R.M., Ruan, Y., Wang, J.S., et al. (2003) Effect of St. John’s Wort on Drug Metabolism by Induction of Cytochrome P450 3A4 Enzyme. The Journal of the American Medical Association, 290, 1500-1504. http://dx.doi.org/10.1001/jama.290.11.1500

[29] Johne, A., Schmider, J., Brockmöller, J., Stadelmann, A., Störmer, E., Bauer, S., et al. (2002) Decreased Plasma Levels of Amitriptyline and Its Metabolites on Comedication with an Extract from St. John's Wort (Hypericum perforatum). Journal of Clinical Psychopharmacology, 22, 46-54. http://dx.doi.org/10.1097/00004714-200202000-00008

[30] Natural Medicine Comprehensive Database (US) (2011) SAMe Full Monograph. http://naturaldatabase.therapeuticresearch.com.proxy.libraries.rutgers.edu/nd/Search.aspx?cs=CEPDA SFS\&s=ND\&pt $=100 \& \mathrm{sh}=1 \& \mathrm{id}=786$

[31] Mischoulon, D. and Fava, M. (2002) Role of S-Adenosyl-L-Methionine in the Treatment of Depression: A Review of the Evidence. The American Journal of Clinical Nutrition, 76, 1158S-1161S.

[32] Saletu, B., Anderer, P., Di Padova, C., Assandri, A. and Saletu-Zyhlarz, G.M. (2002) Electrophysiological Neuroimaging of the Central Effects of S-Adenosyl-L-Methionine by Mapping of Electroencephalograms and Event-Related Potentials and Low-Resolution Brain Electromagnetic Tomography. The American Journal of Clinical Nutrition, 76, 1162S-1171S.

[33] Arnold, O., Saletu, B., Anderer, P., di Padova, C., Corrado, M. and Saletu-Zyhlarz, G.M. (2005) Double-Blind, Placebo-Controlled Pharmacodynamic Studies with a Nutraceutical and a Pharmaceutical Dose of Ademetionine (SAMe) in Elderly Subjects, Utilizing EEG Mapping and Psychometry. European Neuropsychopharmacology, 15, 533-543. http://dx.doi.org/10.1016/j.euroneuro.2005.01.004

[34] Di Rocco, A., Rogers, J.D., Brown, R., Werner, P. and Bottiglieri, T. (2000) S-Adenosyl-Methionine Improves Depression in Patients with Parkinson's Disease in an Open-Label Clinical Trial. Movement Disorders, 15, 1225-1229.

[35] Papakostas, G.I., Mischoulon, D., Shyu, I., Alpert, J.E. and Fava, M. (2010) S-Adenosyl Methionine (SAMe) Augmentation of Serotonin Reuptake Inhibitors for Antidepressant Nonresponders with Major Depressive Disorder: A DoubleBlind, Randomized Clinical Trial. The American Journal of Psychiatry, 167, 942-948. http://dx.doi.org/10.1176/appi.ajp.2009.09081198

[36] Iruela, L.M., Minguez, L., Merino, J. and Monedero, G. (1993) Toxic Interaction of S-Adenosylmethionine and Clomipramine. The American Journal of Psychiatry, 150, 522.

[37] Birdsall, T.C. (1998) 5-Hydroxytryptophan: A Clinically-Effective Serotonin Precursor. Alternative Medicine Review, 3, 271-280.

[38] Turner, E.H., Loftis, J.M. and Blackwell, A.D. (2006) Serotonin a la Carte: Supplementation with the Serotonin Precursor 5-Hydroxytryptophan. Pharmacology \& Therapeutics, 109, 325-338. http://dx.doi.org/10.1016/j.pharmthera.2005.06.004

[39] Natural Medicine Comprehensives Database (US) (2014) L-Tryptophan Full Monograph. http://naturaldatabase.therapeuticresearch.com.proxy.libraries.rutgers.edu/nd/Search.aspx?cs=CEPDA SFS\&s=ND\&pt $=100 \&$ sh=1\&id=326

[40] Natural Medicine Comprehensives Database (US) (2014) 5-HTP Full Monograph. http://naturaldatabase.therapeuticresearch.com.proxy.libraries.rutgers.edu/nd/Search.aspx?cs=CEPDA SFS\&s=ND\&pt $=100 \& \mathrm{sh}=5 \& \mathrm{id}=794$

[41] Van Woert, M.H. and Sethy, V.H. (1975) Therapy of Intention Myoclonus with L-5-Hydroxytryptophan and a Peripheral Decarboxylase Inhibitor, MK 486. Neurology, 25, 135-140. http://dx.doi.org/10.1212/WNL.25.2.135

[42] Van Woert, M.H., Rosenbaum, D., Howieson, J. and Bowers Jr., M.B. (1977) Long-Term Therapy of Myoclonus and Other Neurologic Disorders with L-5-Hydroxytryptophan and Carbidopa. The New England Journal of Medicine, 296, 70-75. http://dx.doi.org/10.1056/NEJM197701132960203

[43] Thal, L.J., Sharpless, N.S., Wolfson, L. and Katzman, R. (1980) Treatment of Myoclonus with L-5-Hydroxytryptophan 
and Carbidopa: Clinical, Electrophysiological, and Biochemical Observations. Annals of Neurology, 7, 570-576. http://dx.doi.org/10.1002/ana.410070611

[44] Haskell, C.F., Dodd, F.L., Wightman, E.L. and Kennedy, D.O. (2013) Behavioral Effects of Compounds Co-Consumed in Dietary Forms of Caffeinated Plants. Nutrition Research Review, 26, 49-70.

http://dx.doi.org/10.1017/S0954422413000036

[45] Hechman, M.A., Weil, J. and Mejia, E.G. (2010) Caffeine (1,3,7-Trimethylxanthine) in Foods: A Comprehensive Review on Consumption, Functionality, Safety, and Regulatory Matters. Journal of Food Science, 75, R77-R87. http://dx.doi.org/10.1111/j.1750-3841.2010.01561.x

[46] DRUGDEX System Micromedex 2.0. (2014) Caffeine. http://www.micromedexsolutions.com.proxy.libraries.rutgers.edu/micromedex2/librarian/ND_T/evidencexpert/ND_PR levidencexpert/CS/10955F/ND_AppProduct/evidencexpert/DUPLICATIONSHIELDSYNC/BEFE12/ND_PG/evidenc ex-

pert/ND_B/evidencexpert/ND_P/evidencexpert/PFActionId/evidencexpert.IntermediateToFullDocumentLink/docId/12 91/contentSetId/31/title/CAFFEINE/servicesTitle/CAFFEINE

[47] Lara, D.R. (2010) Caffeine, Mental Health, and Psychiatric Disorders. Journal of Alzheimer's Disease, 20, S239-248.

[48] Childs, E. and de Wit, H. (2006) Subjective, Behavioral, and Physiological Effects of Acute Caffeine in Light, Nondependent Caffeine Users. Psychopharmacology(Berlin), 185, 514-523. http://dx.doi.org/10.1007/s00213-006-0341-3

[49] Nardi, A.E., Lopes, F.L., Freire, R.C., Veras, A.B., Nascimento, I., Valença, A.M., et al. (2009) Panic Disorder and Social Anxiety Disorder Subtypes in a Caffeine Challenge Test. Psychiatry Research, 169, 149-153. http://dx.doi.org/10.1016/j.psychres.2008.06.023

[50] Bergin, J.E. and Kendler, K.S. (2012) Common Psychiatric Disorders and Caffeine Use, Tolerance, and Withdrawal: An Examination of Shared Genetic and Environment Effects. Twin Research and Human Genetics, 15, 473-482. http://dx.doi.org/10.1017/thg.2012.25

[51] Childs, E., Hohoff, C., Deckert, J., Xu, K., Badner, J. and de Wit, H. (2008) Association between ADROA2A and DRD2 Polymorphisms and Caffeine-Induced Anxiety. Neuropsychopharmacology, 33, 2791-2800. http://dx.doi.org/10.1038/npp.2008.17

[52] Bhatti, S.K., O’Keefe, J.H. and Lavie, C.J. (2013) Coffee and Tea: Perks for Health and Longevity? Current Opinion in Clinical Nutrition and Metabolic Care, 16, 688-697. http://dx.doi.org/10.1097/MCO.0b013e328365b9a0

[53] Ellam, S. and Williamson, G. (2013) Cocoa and Human Health. Annual Review of Nutrition, 33, 105-128. http://dx.doi.org/10.1146/annurev-nutr-071811-150642

[54] De Araujo, Q.R., Gattward, J.N., Almoosawi. S., Silva, M.D.C., Dantas, P.A. and Araujo Jr., Q.R. (2013) Cacao and Human Health: From Head to Foot-A Review. Critical Reviews in Food Science and Nutrition, In Press.

[55] Natural Medicine Comprehensives Database (US) (2013) Cocoa Full Monograph. http://naturaldatabase.therapeuticresearch.com.proxy.libraries.rutgers.edu/nd/Search.aspx?cs=CEPDA SFS\&s=ND\&pt $=100 \& i d=812 \& d s=\& n a m e=$ COCOA\&searchid $=47308599$

[56] Latif, R. (2013) Health Benefits of Cocoa. Current Opinion in Clinical Nutrition and Metabolic Care, 16, 669-674. http://dx.doi.org/10.1097/MCO.0b013e328365a235

[57] Burdock, G.A., Carabin, I.G. and Crincoli, C.M. (2009) Safety Assessment of Kola Nut Extract as a Food Ingredient. Food and Chemical Toxicology, 47, 1725-1732.http://dx.doi.org/10.1016/j.fct.2009.04.019

[58] Natrual Medicine Comprehensive Database (US) (2013) Cola Nut Full Monograph. http://naturaldatabase.therapeuticresearch.com.proxy.libraries.rutgers.edu/nd/Search.aspx?cs=CEPDA SFS\&s=ND\&pt $=100 \& i d=937 \& d s=$ \&name $=$ COLA+NUT\&searchid $=47308599$

[59] Schimpl, F.C., da Silva, J.F., Goncalves, J.F. and Mazzafera, P. (2013) Guarana: Revisiting a Highly Caffeinated Plant from the Amazon. Journal of Ethnopharmacology, 150, 14-31.http://dx.doi.org/10.1016/j.jep.2013.08.023

[60] Natural Medicine Comprehensives Database (US) (2012) Guarana Full Monograph. http://naturaldatabase.therapeuticresearch.com.proxy.libraries.rutgers.edu/nd/Search.aspx?cs=CEPDA SFS\&s=ND\&pt =100\&id=935\&ds=\&name=GUARANA\&searchid=47308599

[61] Silvestrini, G.I., Marino, F. and Cosentino, M. (2013) Effects of a Commercial Product Containing Guaraná on Psychological Well-Being, Anxiety and Mood: A Single-Blind, Placebo-Controlled Study in Healthy Subjects. Journal of Negative Results in BioMedicine, 12, 9.http://dx.doi.org/10.1186/1477-5751-12-9

[62] Berigan, T. (2005) An Anxiety Disorder Secondary to Energy Drinks: A Case Report. Psychiatry, 2, 10.

[63] Wolk, B.J., Ganetsky, M. and Babu, K.M. (2012) Toxicity of Energy Drinks. Current Opinion in Pediatrics, 24, 243251. http://dx.doi.org/10.1097/MOP.0b013e3283506827

[64] Heck, C.I. and De Mejia, E.G. (2007) Yerba Mate Tea (Ilex paraguariensis): A Comprehensive Review on Chemistry, 
Health Implications, and Technological Considerations. Journal of Food Science, 72, R138-R151. http://dx.doi.org/10.1111/j.1750-3841.2007.00535.x

[65] Bracesco, N., Sanchez, A.G., Contreras, V., Menini, T. and Gugliucci, A. (2011) Recent Advances on Ilex paraguariensis Research: Mini Review. Journal of Ethnopharmacology, 136, 378-384. http://dx.doi.org/10.1016/j.jep.2010.06.032

[66] Natural Medicine Comprehensives Database (US) (2013) Mate Full Monograph. http://naturaldatabase.therapeuticresearch.com.proxy.libraries.rutgers.edu/nd/Search.aspx?cs=CEPDA SFS\&s=ND\&pt $=100 \&$ id $=828 \&$ ds $=$ \&name $=$ MATE\&searchid $=47308599$

[67] Natural Standard: The Authority on Integrative Medicine (US) (2014) Khat. https://naturalmedicines.therapeuticresearch.com/databases/food,-herbs-supplements/k/khat/professional.aspx

[68] Wabe, N.T. (2011) Chemistry, Pharmacology, and Toxicology of Khat (Catha edulis Forsk.): A Review. Addiction of Health, 3, 137-149.

[69] Kalix, P. (1991) The Pharmacology of Psychoactive Alkaloids from Ephedra and Catha. Journal of Ethnopharmacology, 32, 201-208. http://dx.doi.org/10.1016/0378-8741(91)90119-X

[70] Patel, N.B. (2000) Mechanism of Action of Cathinone: The Active Ingredient of Khat (Catha edulis). East African Medical Journal, 77, 329-332.

[71] Kalix, P. (1994) Khat, an Amphetamine-Like Stimulant. Journal of Psychoactive Drugs, 26, 69-74. http://dx.doi.org/10.1080/02791072.1994.10472604

[72] Al-Motarreb, A., Baker, K. and Broadley, K. (2002) Khat: Pharmacological and Medical Aspects and Its Social Use in Yemen. Phytotherapy Research, 16, 403-413. http://dx.doi.org/10.1002/ptr.1106

[73] Kalix, P. (1992) Cathinone, a Natural Amphetamine. Pharmacology \& Toxicology, 70, 77-86. http://dx.doi.org/10.1111/j.1600-0773.1992.tb00434.x

[74] Kelly, J.P. (2011) Cathinone Derivatives: A Review of Their Chemistry, Pharmacology and Toxicology. Drug Testing and Analysis, 3, 439-453. http://dx.doi.org/10.1002/dta.313

[75] Geisshusler, S. and Brenneisen, R. (1987) The Content of Psychoactive Phenylpropyl and Phenylpentenyl Khatamines in Catha edulis Forsk. of Different Origin. Journal of Ethnopharmacology, 19, 269-277. http://dx.doi.org/10.1016/0378-8741(87)90004-3

[76] Brenneisen, R., Fisch, H.U., Koelbing, U., Geisshusler, S. and Kalix, P. (1990) Amphetamine-Like Effects in Humans of the Khat Alkaloid Cathinone. British Journal of Clinical Pharmacology, 30, 825-828. http://dx.doi.org/10.1111/j.1365-2125.1990.tb05447.x

[77] Martin, W.R., Sloan, J.W., Sapira, J.D. and Jasinski, D.R. (1971) Physiologic, Subjective, and Behavioral Effects of Amphetamine, Methamphetamine, Ephedrine, Phenmetrazine, and Methylphenidate in Man. Clinical Pharmacology \& Therapeutics, 12, 245-258.

[78] Jager, A.D. and Sireline, L. (1994) Natural History of Khat Psychosis. Australian and New Zealand Journal of Psychiatry, 28, 331-332. http://dx.doi.org/10.3109/00048679409075648

[79] The WHO Expert Committee on Drug Dependence (ECDD) (2006) Assessment of Khat (Catha edulis Forsk.). http://www.who.int/medicines/areas/quality_safety/4.4KhatCritReview.pdf

[80] Hassan, N.A., Gunaid, A.A., El Khally, F.M. and Murray-Lyon, I.M. (2002) The Effect of Chewing Khat Leaves on Human Mood. Saudi Medical Journal, 23, 850-853.

[81] Eckersley, W., Salmon, R. and Gebru, M. (2010) Khat, Driver Impairment and Road Traffic Injuries: A View from Ethiopia. Bulletin of the World Health Organization, 88, 235-236.http://dx.doi.org/10.2471/BLT.09.067512

[82] Randall, T. (1993) Khat Abuse Fuels Somali Conflict, Drains Economy. The Journal of the American Medical Association, 269, 12-15. http://dx.doi.org/10.1001/jama.1993.03500010014004

[83] Drug Enforcement Agency (2012) Drug Fact Sheet. Khat. http://www.justice.gov/dea/druginfo/drug_data_sheets/Khat.pdf

[84] Natural Medicine Comprehensives Database (US) (2014) Yohimbe Full Monograph. http://naturaldatabase.therapeuticresearch.com/nd/Search.aspx?cs=CEPDA SFS\&s=ND\&pt=100\&id=759\&ds=\&name =YOHIMBE\&searchid=47301122

[85] Kunelius, P., Häkkinen, J. and Lukkarinen, O. (1997) Is High-Dose Yohimbine Hydrochloride Effective in the Treatment of Mixed-Type Impotence? A Prospective, Randomized, Controlled Double-Blind Crossover Study. Urology, 49, 441-444. http://dx.doi.org/10.1016/S0090-4295(96)00505-5

[86] Tam, S.W., Worcel, M. and Wyllie, M. (2001) Yohimbine: A Clinical Review. Pharmacology \& Therapeutics, 91, 215-243. http://dx.doi.org/10.1016/S0163-7258(01)00156-5 
[87] Jacobsen, F.M. (1992) Fluoxetine-Induced Sexual Dysfunction and an Open Trial of Yohimbine. The Journal of Clinical Psychiatry, 53, 119-122.

[88] Ernst, E. and Pittler, M.H. (1998) Yohimbine for Erectile Dysfunction: A Systematic Review and Meta-Analysis of Randomized Clinical Trials. The Journal of Urology, 159, 433-436. http://dx.doi.org/10.1016/S0022-5347(01)63942-9

[89] Teloken, C., Rhoden, E.L., Sogari, P., Dambros, M. and Souto, C.A. (1998) Therapeutic Effects of High Dose Yohimbine Hydrochloride on Organic Erectile Dysfunction. The Journal of Urology, 159, 122-124. http://dx.doi.org/10.1016/S0022-5347(01)64032-1

[90] Natural Standard: The Authority on Integrative Medicine (US) (2014) Yohimbe Bark Extract. https://naturalmedicines.therapeuticresearch.com/databases/food,-herbs-supplements/y/yohimbe-bark-extract/professio $\underline{\text { nal.aspx }}$

[91] Morales, A. (2000) Yohimbine in Erectile Dysfunction: The Facts. International Journal of Impotence Research, 12, S70-S74. http://dx.doi.org/10.1038/sj.ijir.3900508

[92] Betz, J.M., White, K.D. and der Marderosian A.H. (1995) Gas Chromatographic Determination of Yohimbine in Commercial Yohimbe Products. Journal of AOAC International, 78, 1189-1194.

[93] Tanaka, M., Yoshida, M., Emoto, H. and Ishii, H. (2000) Noradrenaline Systems in the Hypothalamus, Amygdala and Locus Coeruleus Are Involved in the Provocation of Anxiety: Basic Studies. European Journal of Pharmacology, 405, 397-406. http://dx.doi.org/10.1016/S0014-2999(00)00569-0

[94] Kearney, T., Tu, N. and Haller, C. (2010) Adverse Drug Events Associated with Yohimbine-Contaming Products: A Retrospective Review of the California Poison Control System Reported Cases. The Annals of Pharmacotherapy, 44, 1022-1029. http://dx.doi.org/10.1345/aph.1P060

[95] Susset, J.G., Tessier, C.D., Wincze, J., Bansal, S., Malhotra, C. and Schwacha M.G. (1989) Effect of Yohimbine Hydrochloride on Erectile Impotence: A Double Blind Study. The Journal of Urology, 141, 1360-1363.

[96] Henauer, S.A., Gillespie, H.K. and Hollister, L.E. (1984) Yohimbine and the Model Anxiety State. The Journal of Clinical Psychiatry, 45, 512-515.

[97] Charney, D.S., Heninger, G.R. and Redmond, D.E. (1983) Yohimbine Induced Anxiety And Increased Noadrenergic Function in Humans: Effects of Diazepam and Clonidine. Life Sciences, 33, 19-29. http://dx.doi.org/10.1016/0024-3205(83)90707-5

[98] Vasa, R.A., Pine, D.S., Masten, C.L., Vythilingam, M., Collin, C., Charney, D.S., et al. (2009) Effects of Yohimbine and Hydrocortisone on Panic Symptoms, Autonomic Responses and Attention to Threat in Healthy Adults. Psychopharmacology(Berlin), 204, 445-455. http://dx.doi.org/10.1007/s00213-009-1475-x

[99] Kaplan, J.S., Arnkoff, D.B., Glass, C.R., Tinsley, R., Geraci, M., Hernandez, E., et al. (2012) Avoidant Coping in Panic Disorder: A Yohimbine Biological Challenge Study. Anxiety, Stress \& Coping: An International Journal, 25, 425442. http://dx.doi.org/10.1080/10615806.2011.609587

[100] Charney, D.S., Woods, S.W., Krystal, J.H., Nagy, L.M. and Heninger, G.R. (1992) Noradrenergic Neuronal Dysregulation in Panic Disorder: The Effects of Intravenous Yohimbine and Clonidine in Panic Disorder Patients. Acta Psychiatrica Scandinavica, 86, 273-282. http://dx.doi.org/10.1111/j.1600-0447.1992.tb03266.x

[101] Price, L.H., Charney, D.S. and Heninger, G.R. (1984) Three Cases of Manic Symptoms Following Yohimbine Administration. The American Journal of Psychiatry, 141, 1267-1268.

[102] Albus, M., Zahn, T.P. and Breier, A. (1992) Anxiogenic Properties of Yohimbine. I. Behavioral, Physiological and Biochemical Measures. European Archives of Psychiatry and Clinical Neuroscience, 241, 337-344. http://dx.doi.org/10.1007/BF02191958

[103] Soni, M.G., Carabin, I.G., Griffiths, J.C. and Burdick, G.A. (2004) Safety of Ephedra: Lessons Learned. Toxicology Letters, 150, 97-110. http://dx.doi.org/10.1016/j.toxlet.2003.07.006

[104] Natural Medicine Comprehensives Database (US) (2012) Ephedra. http://naturaldatabase.therapeuticresearch.com.proxy.libraries.rutgers.edu/nd/Search.aspx?cs=CEPDA SFS\&s=ND\&pt $=9 \&$ Product $=$ ephedra\&btnSearch. $x=0 \&$ btnSearch. $y=0$

[105] National Center for Complementary and Alternative Medicine (US) (2013) Ephedra. http://nccam.nih.gov/health/ephedra

[106] Blanck, H., Khan, L. and Serdula, M. (2001) Use of Nonprescription Weight Loss Products: Results from a Multistate Survey. The Journal of the American Medical Association, 286, 930-935. http://dx.doi.org/10.1001/jama.286.8.930

[107] Marraffa, J.M. (2011) Goldfrank’s Toxicologic Emergencies. McGraw-Hill Companies, Inc., China.

[108] Haller, C.A. and Benowitz, N.L. (2000) Adverse Cardiovascular and Central Nervous System Events Associated with Dietary Supplements Containing Ephedra Alkaloids. The New England Journal of Medicine, 343, 1833-1838. http://dx.doi.org/10.1056/NEJM200012213432502 
[109] Food and Drug Administration (2004) Final Rule Declaring Dietary Supplements Containing Ephedrine Alkaloids Adulterated Because They Present an Unreasonable Risk. Federal Register, 69, 6787-6854.

[110] Andraws, R., Chawla, P. and Brown, D.L. (2005) Cardiovascular Effects of Ephedra Alkaloids: A Comprehensive Review. Progress in Cardiovascular Diseases, 47, 217-225. http://dx.doi.org/10.1016/j.pcad.2004.07.006

[111] Woolf, A.D., Watson, W.A., Smolinski, S. and Litovitz, T. (2005) The Severity of Toxicity Reactions to Ephedra: Comparison to Other Botanical Products and National Trends from 1993-2002. Clinical Toxicology, 43, 347-355.

[112] Bent, S., Tiedit, T.N., Odden, M.C. and Shlipak, M.G. (2003) The Relative Safety of Ephedra Compared with Other Herbal Products. Annals of Internal Medicine, 138, 468-471. http://dx.doi.org/10.7326/0003-4819-138-6-200303180-00010

[113] McBride, B.F., Karapanos, A.K., Krudysz, A., Kluger, J., Coleman, C.I. and White, C.M. (2004) Electrocardiographic and Hemodynamic Effects of a Mutlicomponent Dietary Supplement Containing Ephedra and Caffeine. The Journal of the American Medical Association, 291, 216-221. http://dx.doi.org/10.1001/jama.291.2.216

[114] Shekelle, P.G., Hardy, M.L., Morton, S.C., Maglione, M., Mojica, W.A., Suttorp, M.J., et al. (2003) Efficacy and Safety of Ephedra and Ephedrine for Weight Loss and Athletic Performance: A Meta-Analysis. The Journal of the American Medical Association, 289, 1537-1545.

[115] Bents, R.T. and Marsh, E. (2006) Patterns of Ephedra and Other Stimulant Use in Collegiate Hockey Athletes. International Journal of Sport Nutrition and Exercise Metabolism, 16, 636-643.

[116] Palamar, J. (2011) How Ephedrine Escaped Regulation in the United States: A Historical Review of Misuse and Associated Policy. Health Policy, 99, 1-9. http://dx.doi.org/10.1016/j.healthpol.2010.07.007

[117] Natural Medicine Comprehensives Database (US) (2012) Country Mallow Full Monograph. http://naturaldatabase.therapeuticresearch.com/nd/Search.aspx?cs=CEPDA SFS\&s=ND\&pt=100\&id=837\&ds=\&name =COUNTRY+MALLOW\&searchid=47301122

[118] Natural Standard: The Authority on Integrative Medicine (US) (2014) Bala. https://naturalmedicines.therapeuticresearch.com/databases/food,-herbs-supplements/b/bala/professional.aspx

[119] Franzotti, E.M., Santos, C.V.F., Rodrigues, H.M.S.L., Mourao, M.R., Andrade, M.R. and Antoniolli, A.R. (2000) AntiInflammatory, Analgesic Activity and Acute Toxicity of Sida cordifolia L. (Malva-Branca). Journal of Ethnopharmacology, 72, 273-278. http://dx.doi.org/10.1016/S0378-8741(00)00205-1

[120] Kanth, V.R. and Diwan, P.V. (1999) Analgesic, Antiinflammatory and Hypoglycaemic Acitivities of Sida cordifolia. Phytotherapy Ressearch, 13, 75-77.

[121] Momin, M.A., Bellah, S.F., Rahman, S.M., Rahman, A.A., Murshid, G.M. and Emran, T.B. (2014) Phytopharmacological Evaluation of Ethanol Extract of Sida cordifolia L. Roots. Asian Pacific Journal of Tropical Biomedicine, 4, 1824. http://dx.doi.org/10.1016/S2221-1691(14)60202-1

[122] Konaté, K., Bassolé, I.H., Hilou, A., Aworet-Samseny, R., Souza, A., Barro, N., et al. (2012) Toxicity Assessment and Analgesic Activity Investigation of Aqueous Acetone Extracts of Sida acuta Burn F. and Sida cordifolio L. (Malvaceae), Medicinal Plants of Burkina Faso. BMC Complementary \& Alternative Medicine, 12, 120-131. http://dx.doi.org/10.1186/1472-6882-12-120

[123] Thompson, C.A. (2004) Ephedrine Alkaloids Banned from Dietary Supplements. American Journal of Health-System Pharmacy, 61, 750-753. 
Scientific Research Publishing (SCIRP) is one of the largest Open Access journal publishers. It is currently publishing more than 200 open access, online, peer-reviewed journals covering a wide range of academic disciplines. SCIRP serves the worldwide academic communities and contributes to the progress and application of science with its publication.

Other selected journals from SCIRP are listed as below. Submit your manuscript to us via either submit@scirp.org or Online Submission Portal.
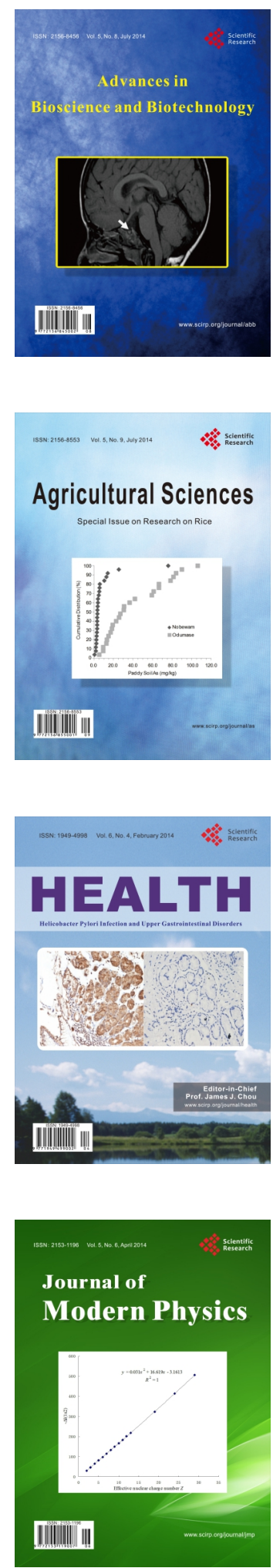
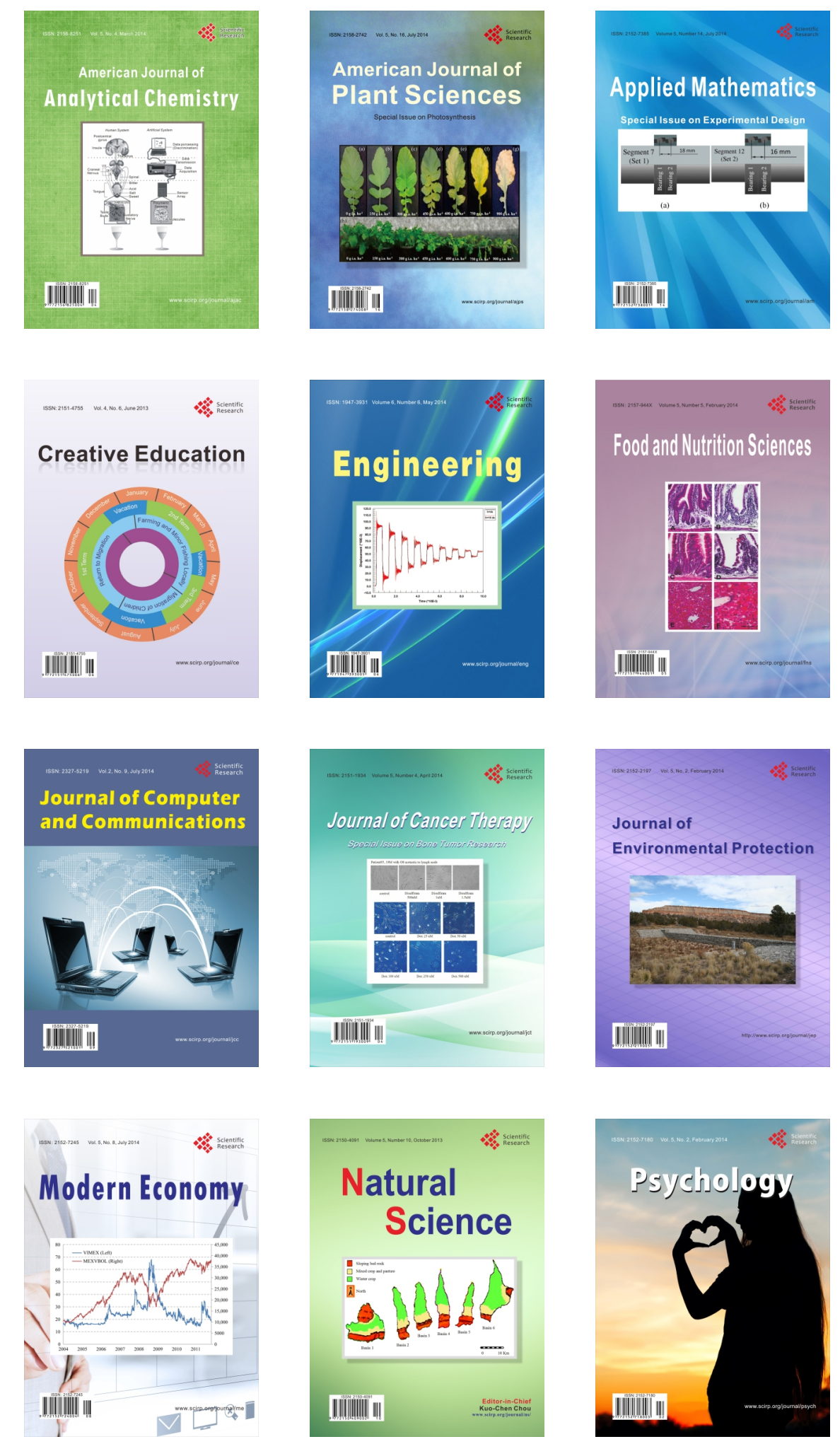